\title{
Research Paper \\ Verbal Fluency Performance in Normal Elderly Persian Speakers
}

\author{
Vahideh Mohammadisabet ${ }^{1}$, ${ }^{*}$ Fariba Yadegari ${ }^{1}$, Mahshid Foroughan ${ }^{2}$
}

1. Department of Speech Therapy, University of Social Welfare and Rehabilitation Sciences, Tehran, Iran.

2. Iranian Reaserch Center on Aging, University of Social Welfare and Rehabilitation Sciences, Tehran, Iran.

Chtation: Mohammadisabet V, Yadegari F, Foroughan M. [Verbal fluency performance in normal elderly Persian speakers (Persian)]. Iranian Journal of Ageing. 2016; 11(2):290-299. http://dx.crossref.org/10.21859/sija-1102290

: http://dx.crossref.org/10.21859/sija-1102290

Received: 10 Mar 2016 Accepted: 22 May 2016

Key words: Word finding, Verbal fluency, Aging, Cognitive decline

\begin{abstract}
AB STRACT
Objectives Cognitive deficits and language disorders such as difficulty in recalling certain words are common among the elderly people. Verbal fluency as an index of word finding is one of the first cognitive functions that decline due to aging.-Considering the lack of norms of verbal fluency in normal elderly Persian-speakers, the purpose of this research was to determine verbal fluency performance in elderly Persian speakers.

Methods \& Materials This observational study consisted of 90 normal elderly individuals aged below 60 years, of which 45 were females and 45 were males. They were categorized into two age groups (60-74 years old, $75-90$ years old) and three educational groups ( $<5,6-12$ years old, $<12$ years). A verbal fluency test was administered in two parts consisting of a semantic fluency measure in which the participants were required to name sequences from semantic categories and another phonemic fluency task (FAS) which was required to be completed in 60 seconds. Responses were audio-recorded, transcribed, and analyzed using the Troyer method. Data were analyzed using independent t-test, ANOVA and Pearson correlation coefficient.

Results The findings of this study did not reveal any significant differences in the mean scores for semantic and phonemic fluency between both the genders. However, significant differences in mean scores were found in semantic and phonemic fluency between age groups $(P<0.001)$. A significant revere correlation was found between age and switching $(r=0.46 \mathrm{P}<0.01)$. Education also showed a positive correlation with switching $(r=0.36, \mathrm{P}<0.01)$.

Conclusion The finding of the present study showed that semantic and phonemic fluency degrades through aging and enhances with higher education. Gender has no effect on semantic and phonemic fluency. It appears that the decline of verbal fluency due to aging should be considered in rehabilitation programs of language deficits such as aphasia in elderly people.
\end{abstract}

\section{* Corresponding Author:}

Fariba Yadegari, PhD

Address: Department of Speech Therapy, University of Social Welfare and Rehabilitation Sciences, Koodakyar Ave., Daneshjoo Blvd., Evin, Tehran, Iran. Tel: +98 (21) 22180043

E-mail: faribayadegari@yahoo.com 


\title{
بررسى روانى واجى و روانى معنايى در سالمندان سالم فارسىزبان
}

\author{
وحيده محمدى ثابت' ، “فريبا يادكارى'، مهشيد فروغان' \\ ا-كروه كفتاردرمانى، دانشعاه علوم بهزيستى و توانبخشى، تهران، ايران. \\ ك- مركز تحقيقات سالمندى ايران، انشكاه علوم بيزيستى و توانبخشى، تيران، ايران.
}

\begin{abstract}
حكSי

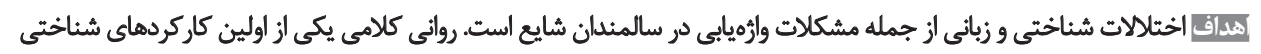

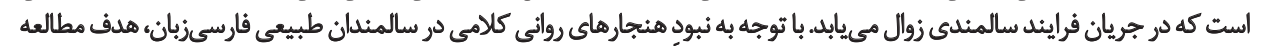

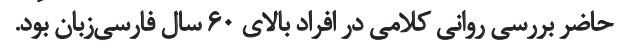

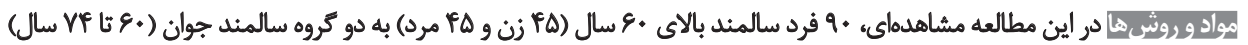

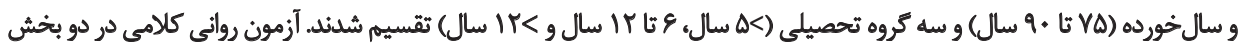

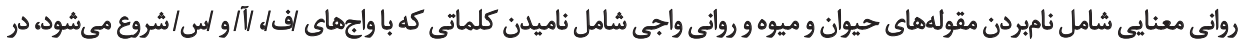

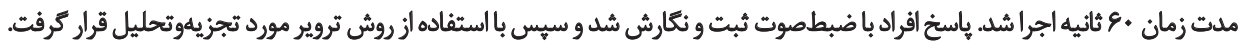

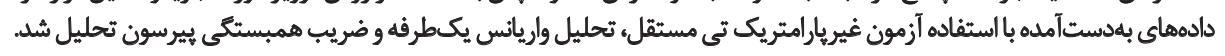

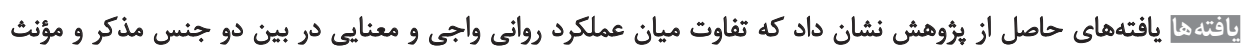

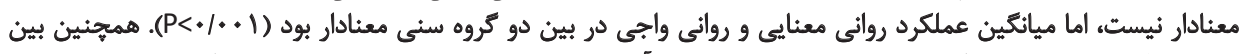

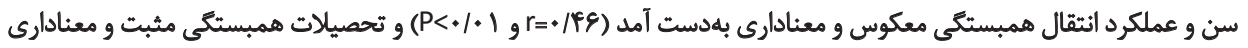

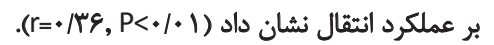

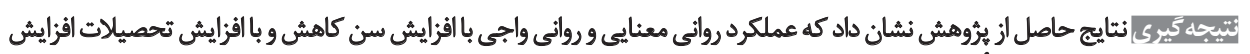

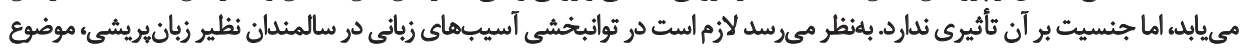

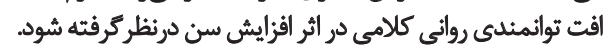

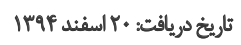

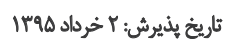

كليدوارهها:

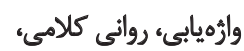

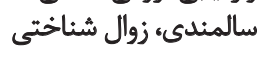

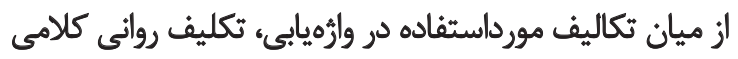

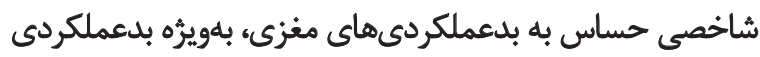

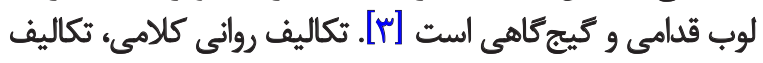

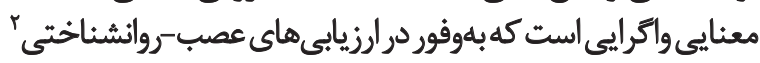

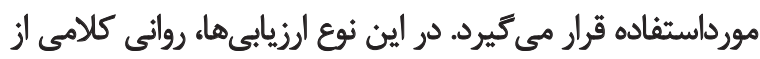

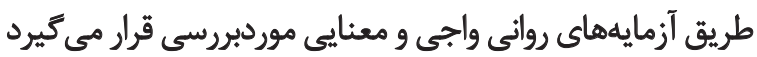

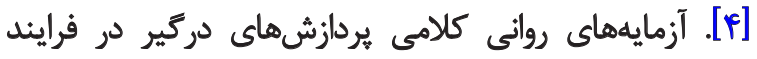

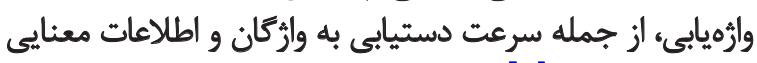

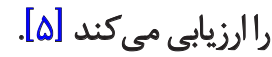

2. Neuropsychological assessment

\begin{abstract}
مقدمه
اختّلال در وارهيابي، دستهبندى، نامكذارى و انتخاب يا يأيناي

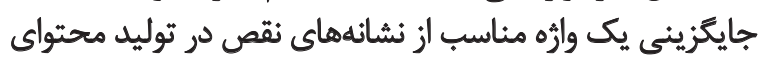

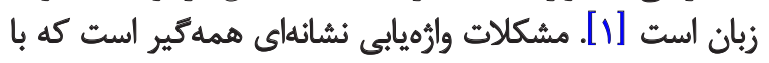

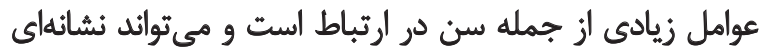

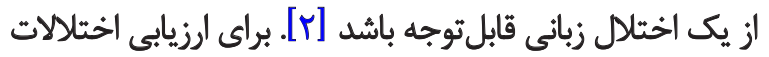

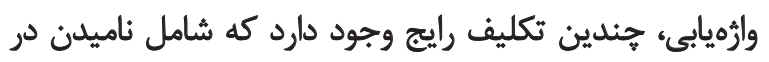

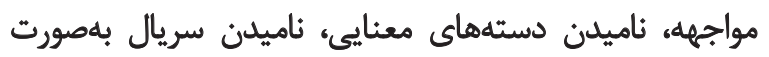
خودكار، تكرار و روانى كُفتار' (روائى كلامي) است ناميد [1]
\end{abstract}

1. Verbal fluency

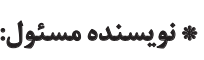

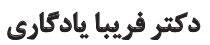

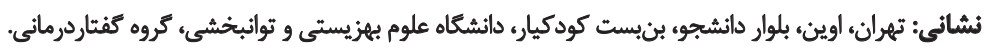

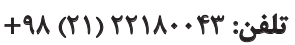
faribayadegari@yahoo.com بـت الكترونيكي 
تحتثأثير سن و تحصيلات قرار دارد، درحالى كه جنسيث بر آن تأثيرى ندارد [هائ]

سالمندى با كاهش توانايىهاى شناختى همراه است [9].

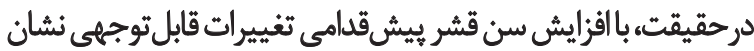

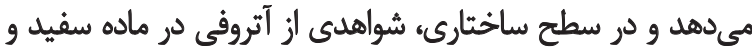

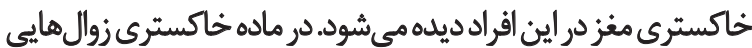

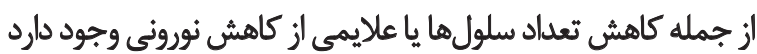

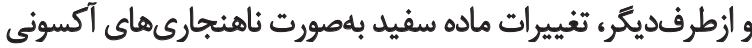

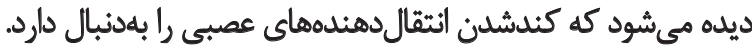

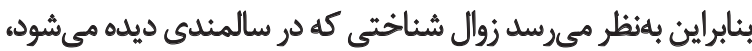
بهواسطه تغييرات ماده سفيد در مغز ايجاد مى شود [ـ [1]. سالمندان طبيعى زوال شناختى را دست بم در يكي از موارد

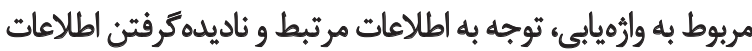

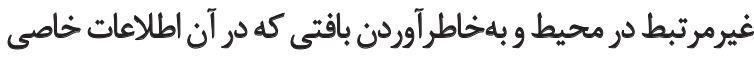

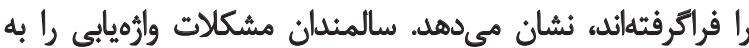

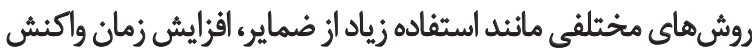

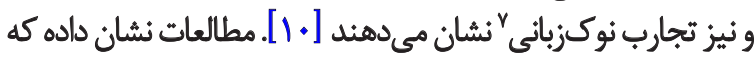

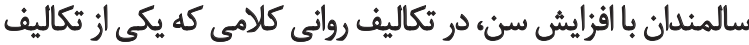

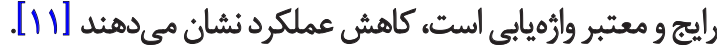

جمعيت سالمثدان جهان درحالفأفزايش است و كشور ما نيز از اين بين

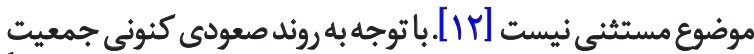

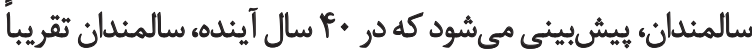

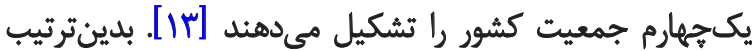

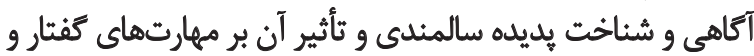

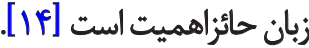

با توجه به نأثير فرهنك و زبان بر عملكرد روانى كلامى، نقش

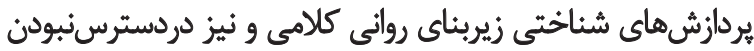

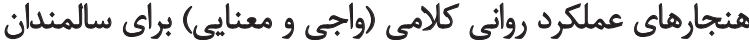

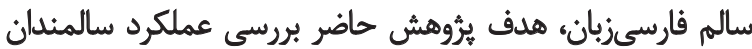

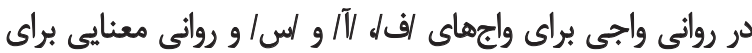

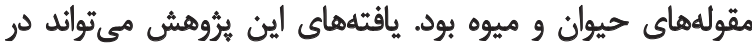

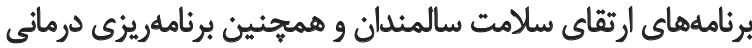

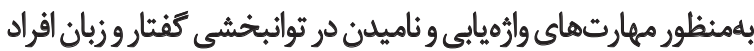

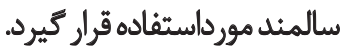

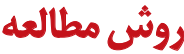

:ثروهش حاضر، مطالعهاى مشاهدهاى بود كه بلهورمقطعى انجام

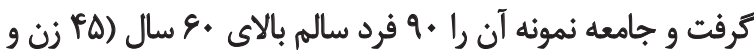

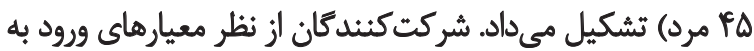

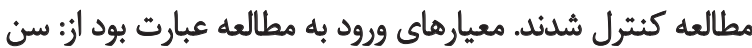

7. Tip- of-the-tongue

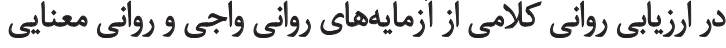

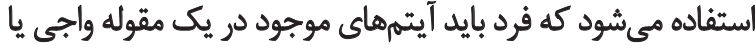

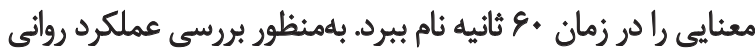

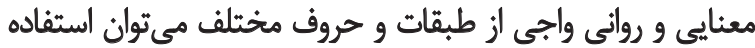

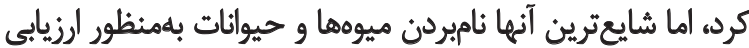

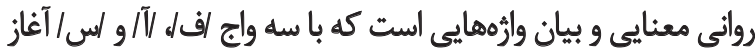

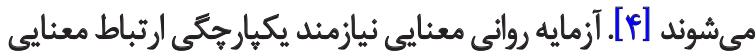

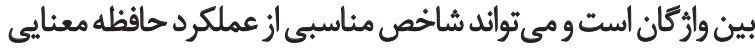

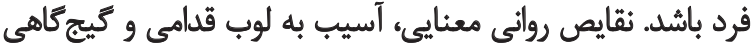

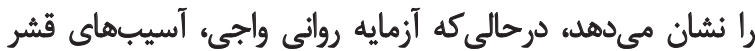

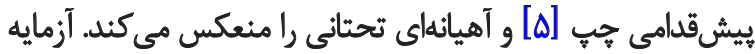

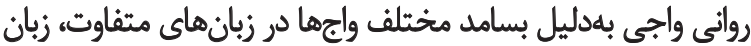

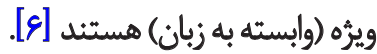

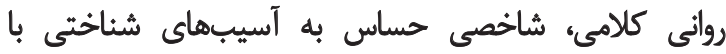

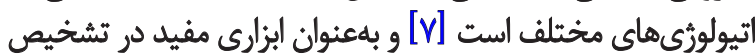

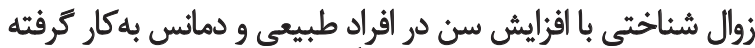

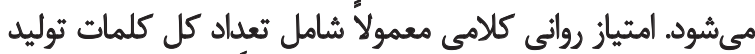

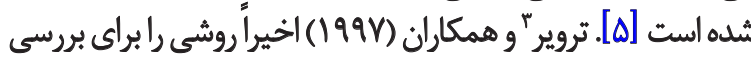

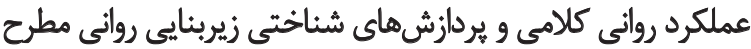

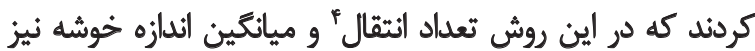

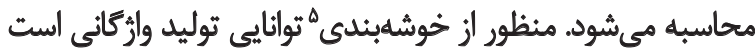

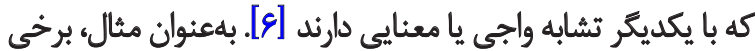

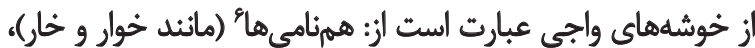

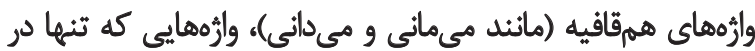

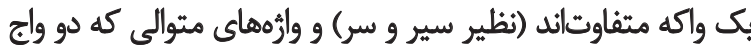

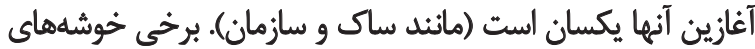

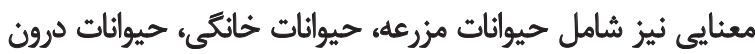

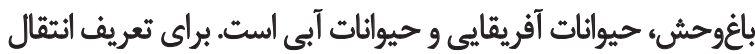

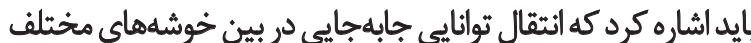

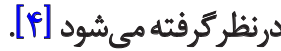

مطالعات مختلف تأثير عواملى مانند جنسيت، سن و تحصيلات

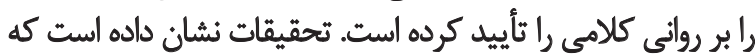

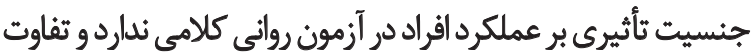

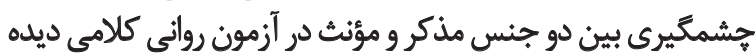

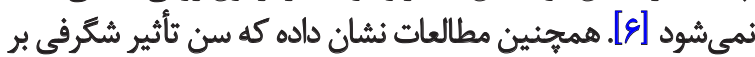

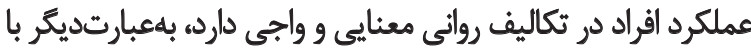

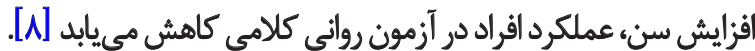

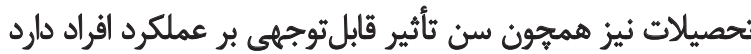

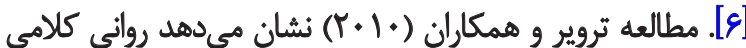

3. Troyer

4. Switching

5. Clustering

6. Homonym 
براى اجراى آزمون از وى كسب مىشد. سيس ويرّكى هاى

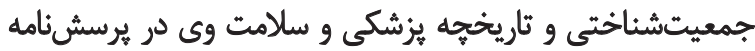
اطلاعات فردى ثبت مىشد.

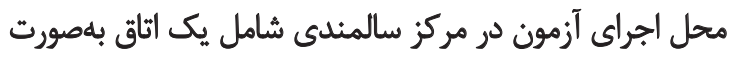

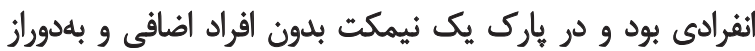

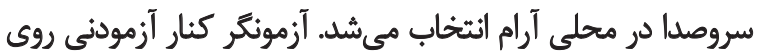

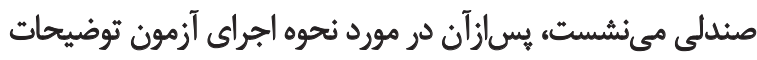

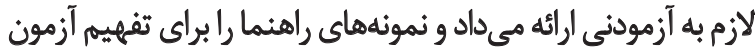

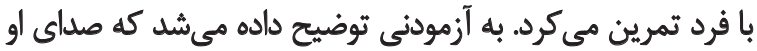

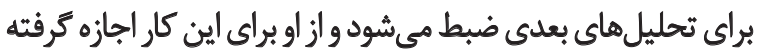

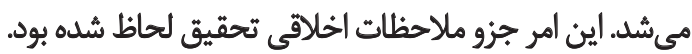

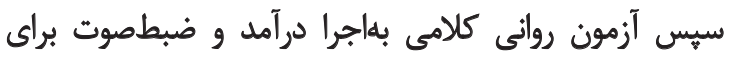

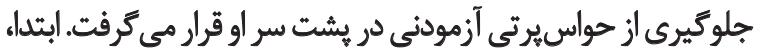

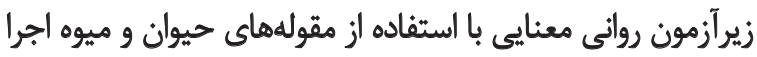

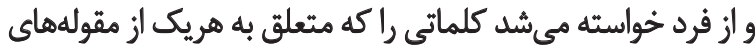

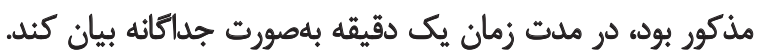

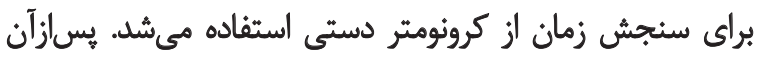

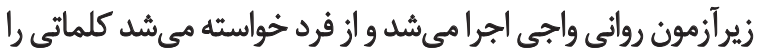

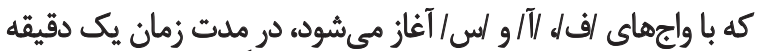

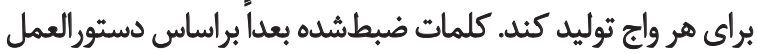

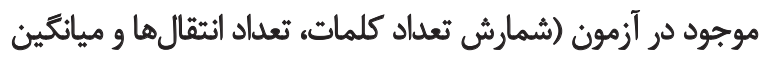

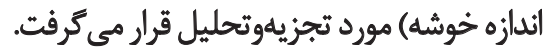

آزمونى كه در اين مطالعه مورداستفاده قرار كرفت، آزمون

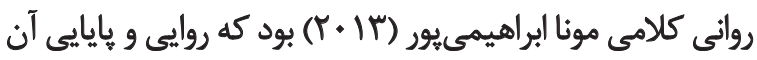

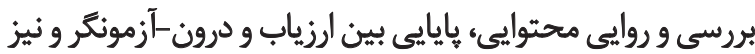

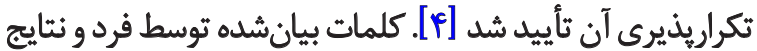

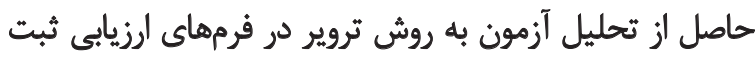

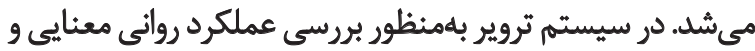

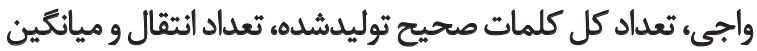
اندازه خوشه در هر تكليف (حيوانات، ميوهها و حروف لآله الف/ و و

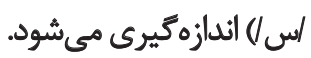

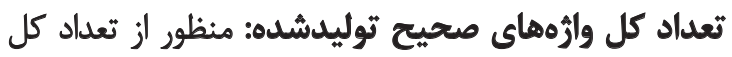

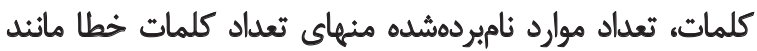

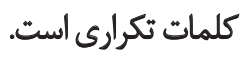

ميانكين اندازه خوشه: در اين روش براى شمارش خوشهائ

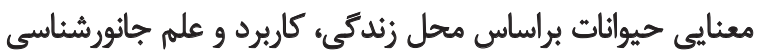

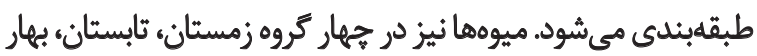

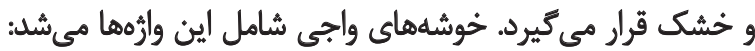

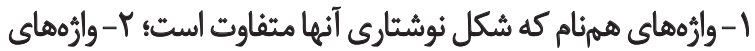

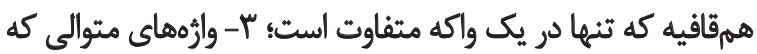

$$
\text { دو حرف آغازين آنها يكسان است }
$$

بالاى •و سال سالمندان، زبان فارسى بهعنوان زبان مادرى يا غالب آنها و داشتن حداقل تحصيلات ابتدايى. نالئ.

معيارهاى خروج از مطالعه را اين موارد دربرمى مرفت: سابقه

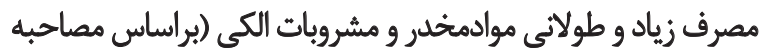

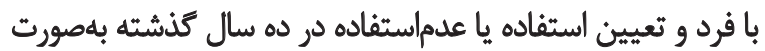

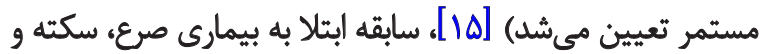

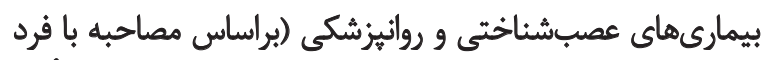

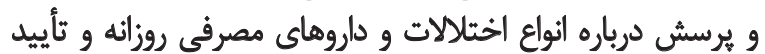

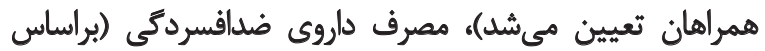

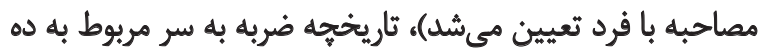

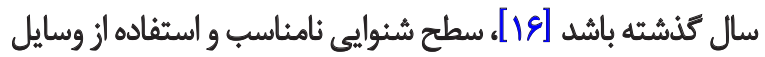

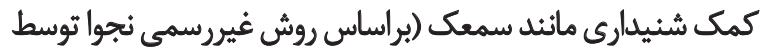

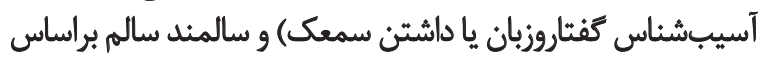

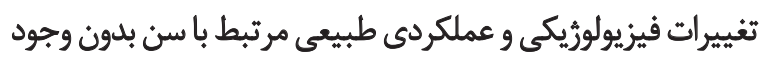

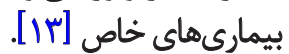

در اين مطالعه تحصيلات بلعنوان يك ملاك درنظركرفته شده بود

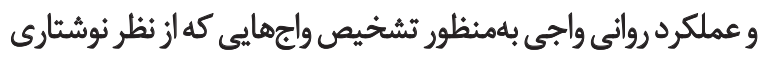

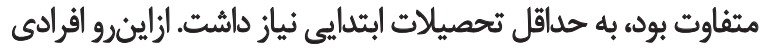

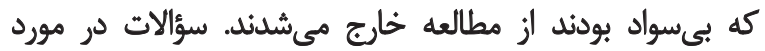

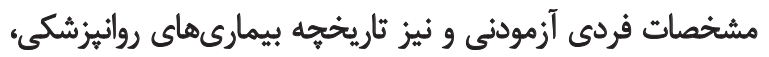

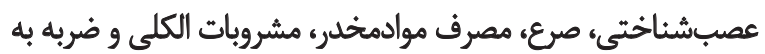
سر با دقت كامل در يرسشنامه اطلاعات فردى و رضايتنامه ثبت مريت مي مشد.

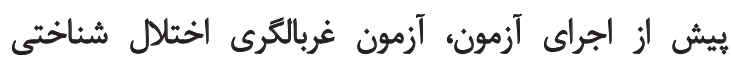

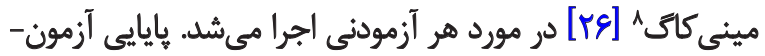

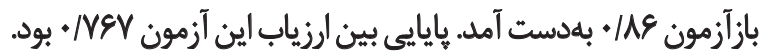

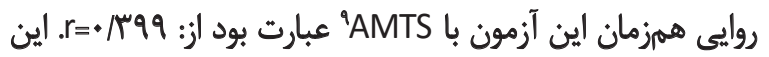

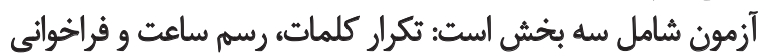

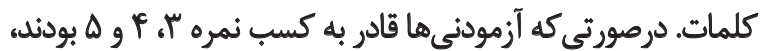

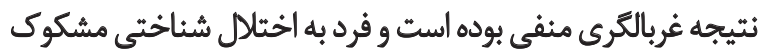

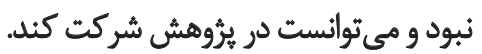

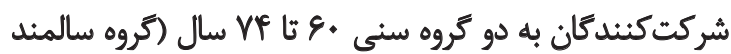

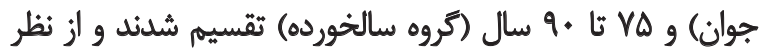

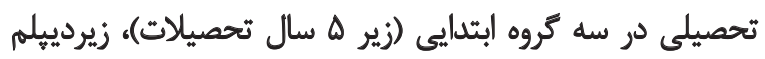

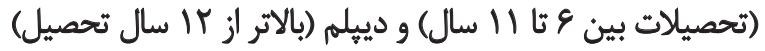

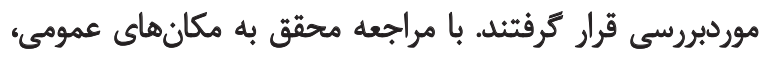

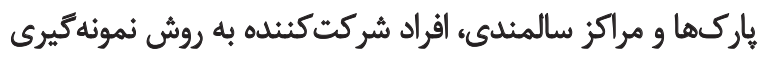

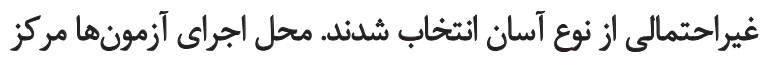

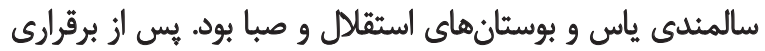
ارتباط با آزمودنى با رعايت كدهاي اخلاقى مرتبط، رضايت لازم برد بردي

8. Mini-cog

9. Abbreviated Mental Test Score (AMTS) 


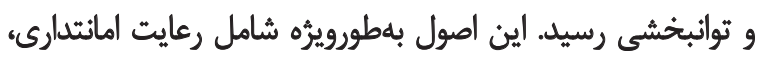

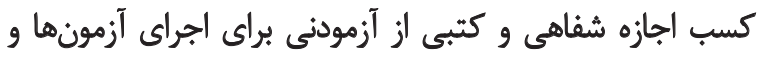

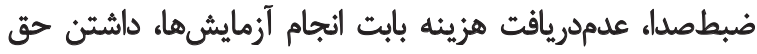

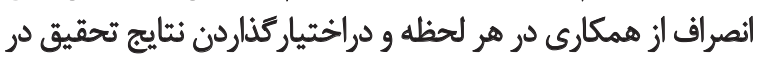
صورت درخواست آزمودنى بود.

يافتهها

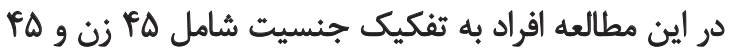

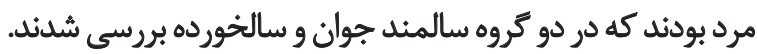

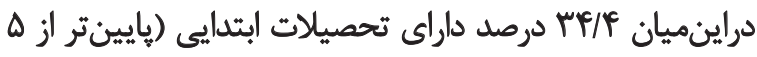

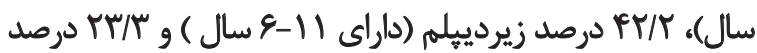

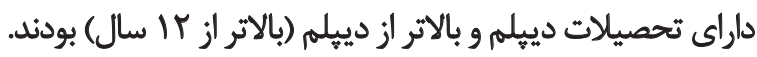

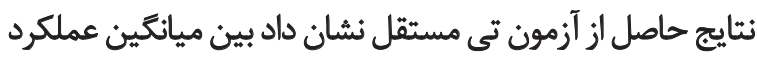

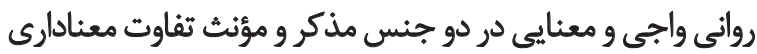

$$
\text { وجود ندارد (جدول شماره (1). }
$$

بين ميانكين عملكرد روانى واجى و معنايى در كروه سالمند

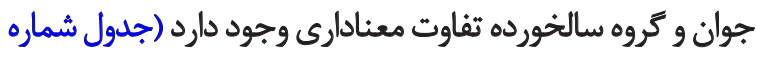

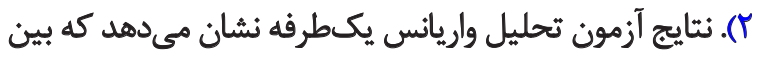

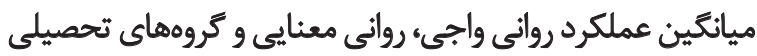

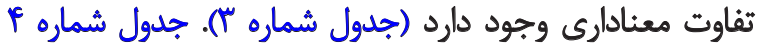

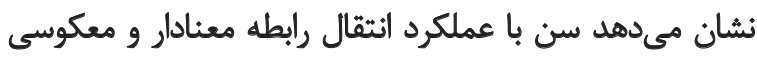

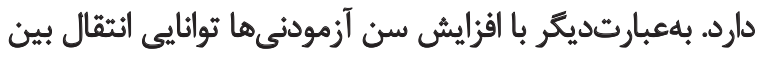

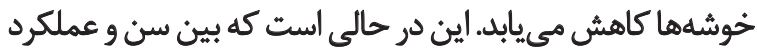

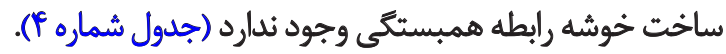

براساس نتايج جدول شماره ه تحصيلات با عملكرد انتقال
براى محاسبه ميانكين اندازه خوشه در هر تكليف، ابتدا اندازه

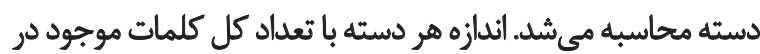

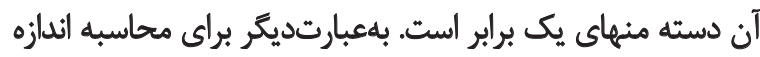

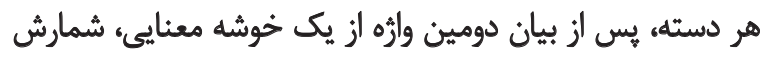

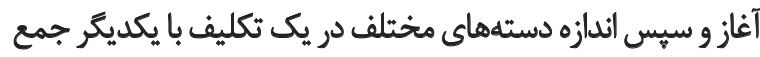

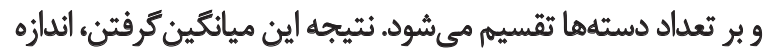

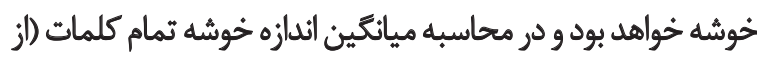
جمله خطاها) محاسبه مي شودود.

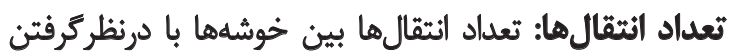

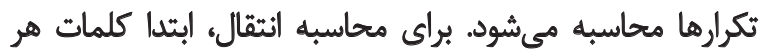

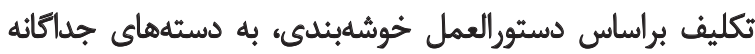

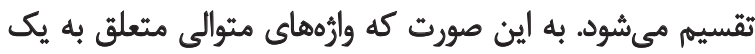

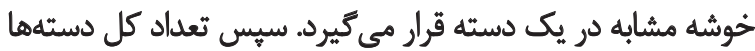

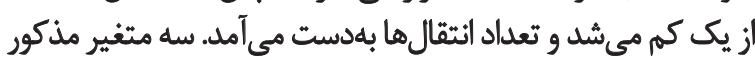

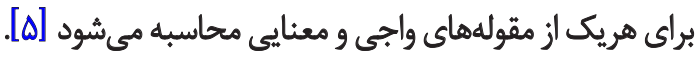

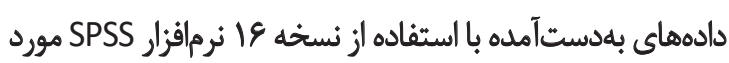

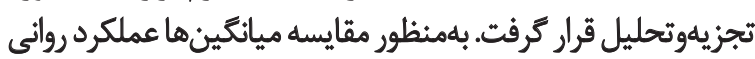

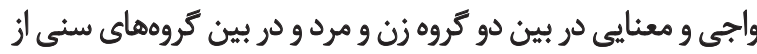

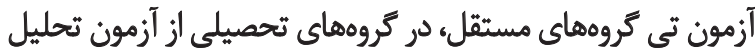

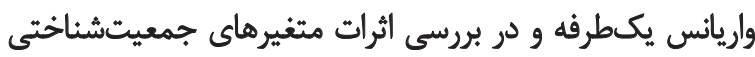

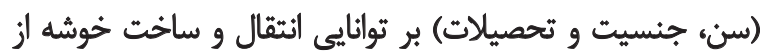

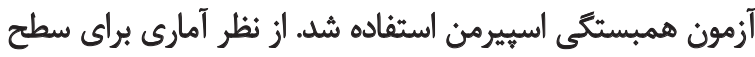

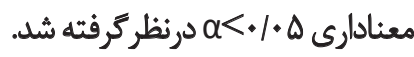

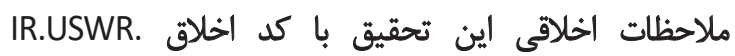

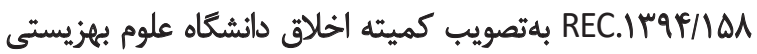

جدول ا. محاسبه ميانكين و انحرافٔمعيار شاخصهاى روانى واجى و روائى معنايى در بين دو جنس مرد و زن.

\begin{tabular}{|c|c|c|c|c|c|c|}
\hline P-value & آماره t & انحرافمعيار & مياتكين & تعداد & جنسيت & تكليف \\
\hline \multirow{2}{*}{ - /Ra } & $-|V|$ & $V \cdot r$ & M & Fo & 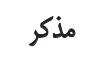 & \multirow{2}{*}{ روائى واجى (تعلاد كلمات صحيح) } \\
\hline & $-|V|$ & 1.111 & 19/4T & Po & مؤنث & \\
\hline \multirow{2}{*}{.$/ 1 f$} & $-\mid F N$ & Q/TA & $T V / \Delta D$ & fo & هذكر & \multirow{2}{*}{ روائى معنايع (تعداد كلمات صحيح) } \\
\hline & $-F N \mid$ & V/AV & $r \cdot / r f$ & Pa & هوْنث & \\
\hline
\end{tabular}

L

جدول r. محاسبه ميائكين و انحرافمعيار شاخصهاى روائى واجى و روائى معنايى افراد در بين كروههاى سنى (سالمند جوان و سالخورده).

\begin{tabular}{|c|c|c|c|c|c|c|}
\hline P-value & آماره t & أتحرافمعيار & مياتكين & تعداد & كروه سنى & تكليف \\
\hline \multirow{2}{*}{$.1+\infty 1$} & t/MF & $1 / 11$ & Tr/OF & te & $8 \cdot-h^{c}$ & \multirow{2}{*}{ روائى واجى (تعداد كلمات } \\
\hline & F/TF & $1 / 4 A$ & $I f / N$ & HF & $V Q-q$. & \\
\hline \multirow{2}{*}{$+10+1$} & r/go & NMF & "I/9ه & fe & $g \cdot-h^{f}$ & \multirow{2}{*}{ وانتى معنائى (تعلداد كلمات } \\
\hline & r/FQ & V/AV & $r \Delta / \mathrm{V}$ & pr & $V \Delta-q$. & \\
\hline
\end{tabular}

L 
جدول ". محاسبه ميانكين و انحرافمعيار شاخصهاى روانى واجى و روانى معنايي در بين گروهاي تحصيلى مختلف.

\begin{tabular}{|c|c|c|c|c|c|}
\hline P-value & اتحراقمعيار & مياتكين & تعداد & تحصيلات & تكليف \\
\hline \multirow{3}{*}{$.1 .+1$} & S/PD & $I r / g V$ & r & يايينتر از ه سال & \multirow{3}{*}{ روانى واجى } \\
\hline & $9 / 1$ & $|N T|$ & ra & ع تا II سال & \\
\hline & NAS & $r V / \cdot F^{e}$ & M & بالاتر از rا سال & \\
\hline \multirow{3}{*}{.1 .4} & $V / T A$ & re & m & يايينتر از هـ سال & \multirow{3}{*}{ رواني معنايي } \\
\hline & NAY & $r q / 8 A$ & rA & ع نا II سال & \\
\hline & NAY & rive & r) & بالاتر از r السال & \\
\hline
\end{tabular}

㫛

جدول F. ميزان ارتباط سن با عملكرد انتقال وخوشهسازى در كروه سالمند جوان و مروه سالخورده.

\begin{tabular}{|c|c|c|c|c|c|c|}
\hline \multirow{3}{*}{ معنادارى } & \multirow{3}{*}{ ضريب همبيستكي } & \multicolumn{4}{|c|}{ كروه سنى } & \multirow{3}{*}{ متغير } \\
\hline & & \multicolumn{2}{|c|}{ سالخهورده } & \multicolumn{2}{|c|}{ سالمند جوان } & \\
\hline & & انحر افمعيار & ميانكين & أتحرافمعيار & مياتكين & \\
\hline .11 & $-+/ 48$ & $\Delta / A C$ & $|r / \pi|$ & $\Delta / \Delta A$ & $I V / T A$ & ت تعلداد كل انثقال \\
\hline.$/ \mu$ &.$/$ & $\cdot / \pi \Delta$ & $\cdot / M$ &.$/ 4 t$ & $\cdot / A r$ & اندازه خوشه كل \\
\hline
\end{tabular}

L

جدول هـ ميزان ارتباط تحصيلات با عملكرد انثقال و خوشه سازي در كروههاي تحصيلي مختلف.

\begin{tabular}{|c|c|c|c|c|c|c|c|c|}
\hline \multirow{3}{*}{ معنادارى } & \multirow{3}{*}{ ضريب همبستّكى } & \multicolumn{6}{|c|}{ ئروه تحصيلي } & \multirow{3}{*}{ مثغير } \\
\hline & & \multicolumn{2}{|c|}{ بالاتر از Yا سال } & \multicolumn{2}{|c|}{ عتا |ل سال } & \multicolumn{2}{|c|}{ هايينتر از ه سال } & \\
\hline & & انحرافمعيار & مياتكين & انحرافمعيار & مياتكين & انحر|أقمعيار & مياتكين & \\
\hline $.1+\infty 1$ &.$/ T e$ & ه/99 & $19 \cdot r$ & E/DP & $1 F / m$ & $P / D$ & Ir/EV & تعلداد كل اثثقال \\
\hline$\cdot / A V$ & .1 .18 & . &.$/ N A$ &.$/ 4 q$ & . A9Y &.$/ p$ & . $/ A Y$ & أندازه خوُشه كل \\
\hline
\end{tabular}

乩

جدول و. ميزان ارتباط جنسيت با عملكرد ائتقال و خوشهازى در كروهاى جنسى مذكر و مؤنث.

\begin{tabular}{|c|c|c|c|c|c|c|}
\hline \multirow{3}{*}{ معنادارى } & \multirow{3}{*}{ ضريب همبستكى } & \multicolumn{4}{|c|}{ كروه جنسى } & \multirow{3}{*}{ مثغير } \\
\hline & & \multicolumn{2}{|c|}{ مؤنث } & \multicolumn{2}{|c|}{ مذكر } & \\
\hline & & انحرافمعيار & ميائكين & انحرافهعيار & مياتكين & \\
\hline$\cdot 1 \cdot \Delta$ &.$/ r$ & g/m & $18 / 11$ & $\Delta / A f$ & Ir/OF & تعداد كل ائثقال \\
\hline.$/ p 8$ & $-1.1 \cdot 19$ & $\cdot / M T$ &.$/ 19$ & . IQr &.$/ 91$ & اندازه خوشه كل \\
\hline
\end{tabular}

故

رابطه مستقيهم و معنادارى دارد. بهعبارتديكر، با افزايش سطح

اين مطالعه با هدف دستيابى به هنجارهاي عملكرد افراد سالمند

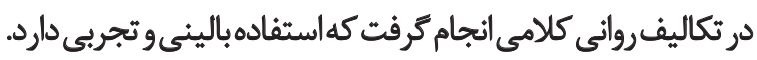

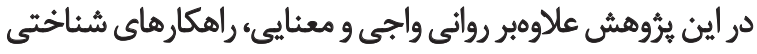

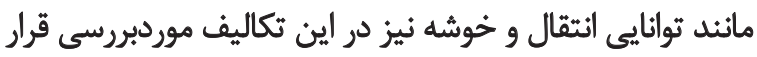

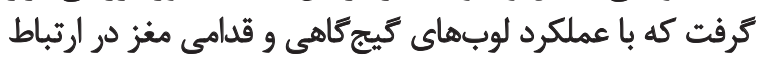

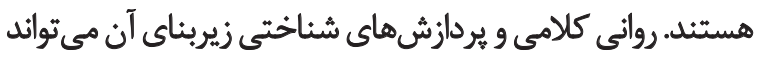

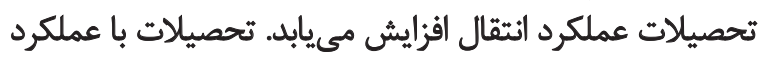

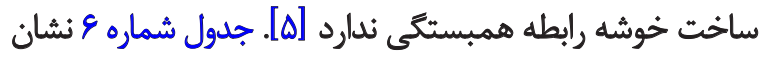

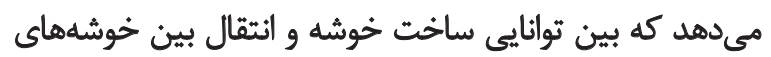

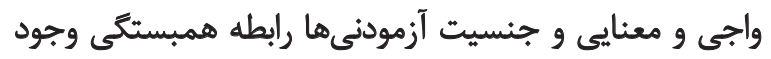

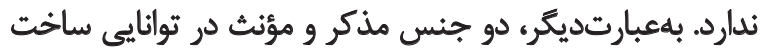

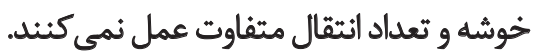


نتايج يُروهش حاضر حاكى از آن است كه عملكرد رواني واجي

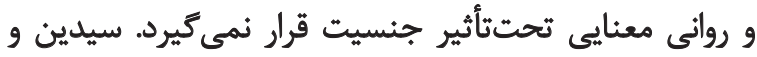

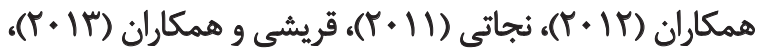

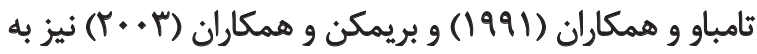

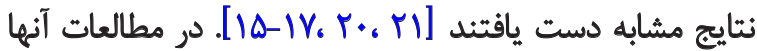

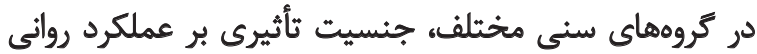

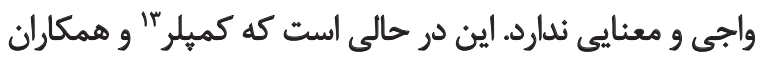

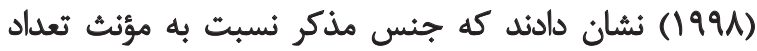

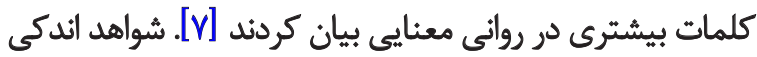

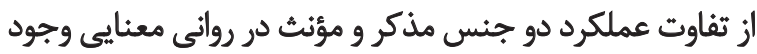

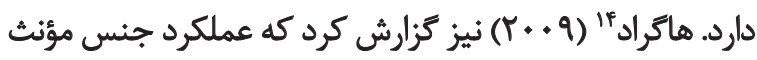

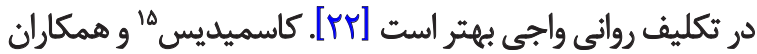

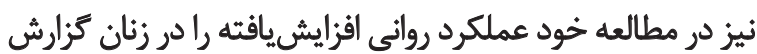

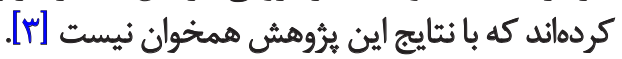

اين مطالعه ارتباط معكوس و معنادار بين سن و تعداد انتقال ها

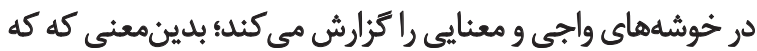

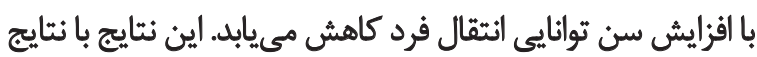

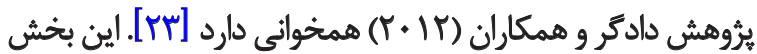

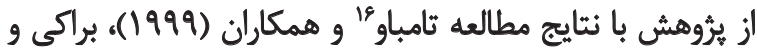

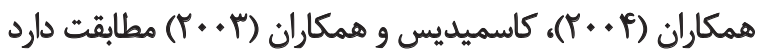

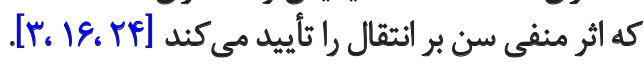
درحقيقت فرايند انتقال در روانى كلامى، راهكارهاى جستجو

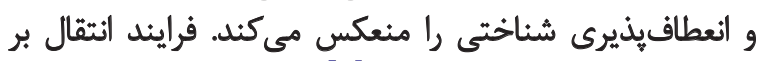

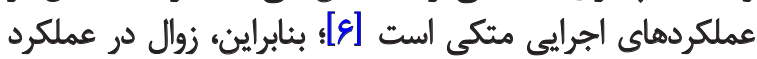

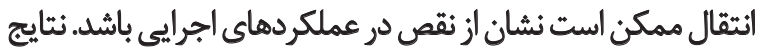

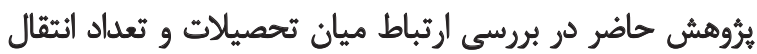

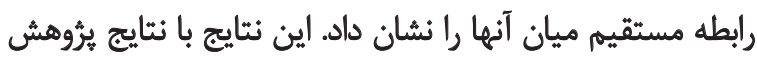

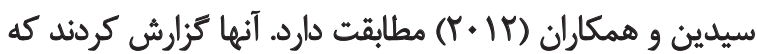

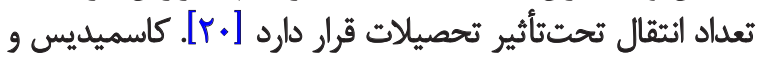

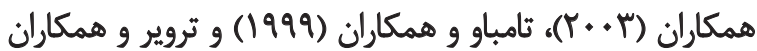

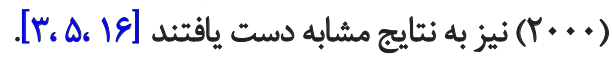

يثروهش حاضر نشان مىدهد توانايى ساخت خوشه در

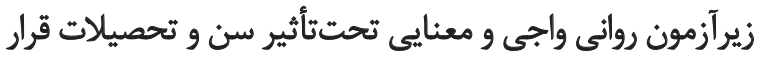

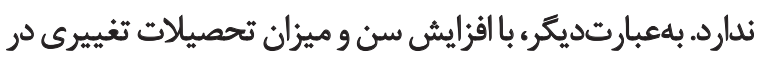

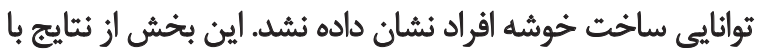

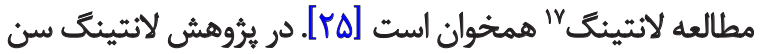

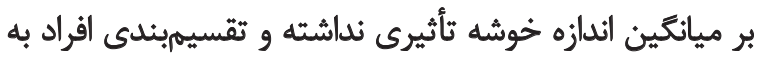

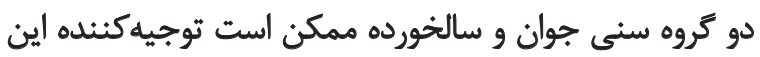

13. Kempler

14. Haugrud

15. Kosmidis

16. Tombaugh

17. Lanting

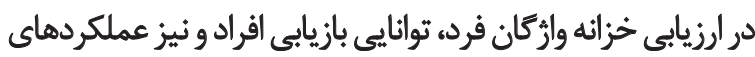

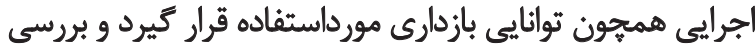

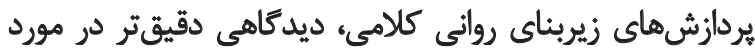

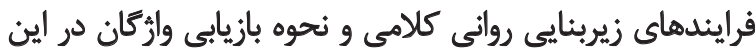
تكاليف رادر اختيار افراد قرار دهد.

نتايج يثروهش حاضر نشان مىدهد روائى واجى و معنايى با

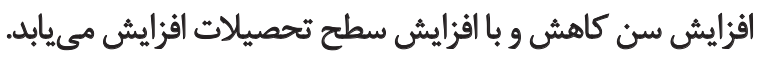

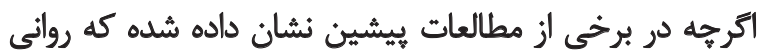

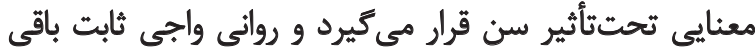

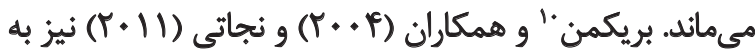

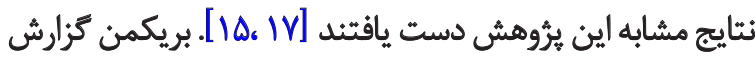

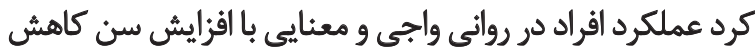

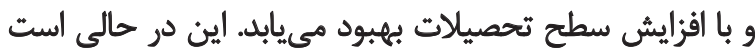

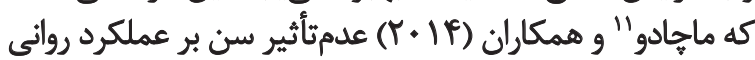

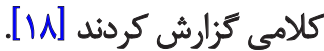

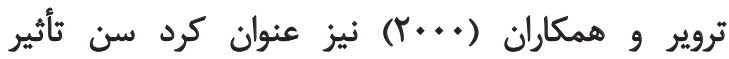

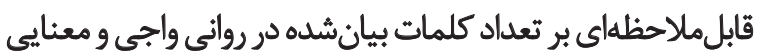

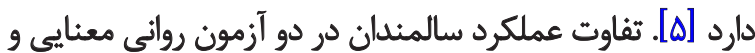

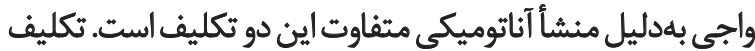

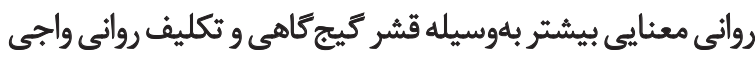

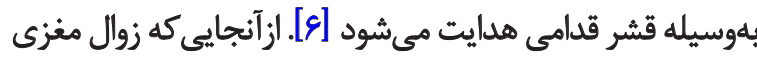

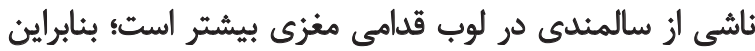

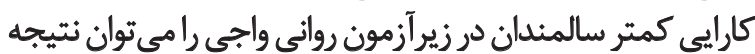

$$
\text { اين تغيير ساختارى دانست. }
$$

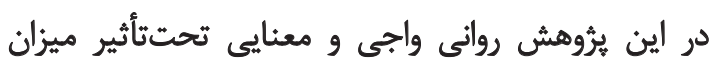

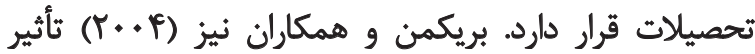

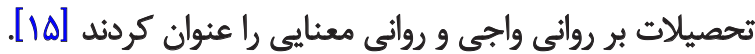

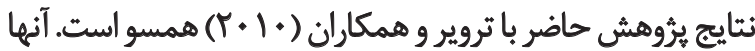

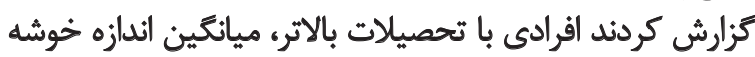

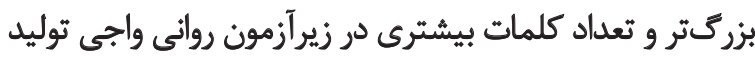

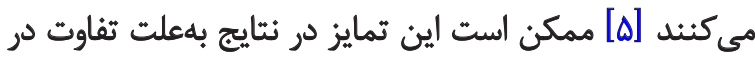

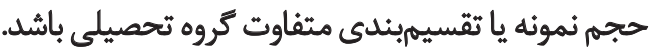

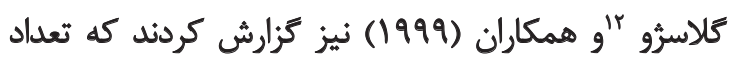

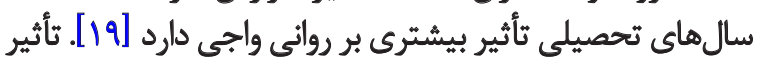

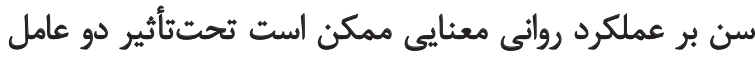

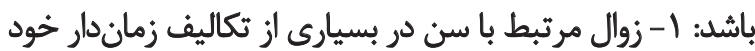

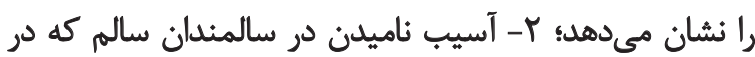

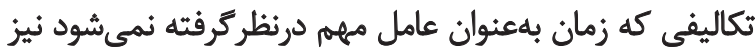

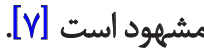

10. Brickman

11. Machado

12. Gladsjo 
شناختى هستند در مقايسه با سالمندان سالم اجرا شود، امكان

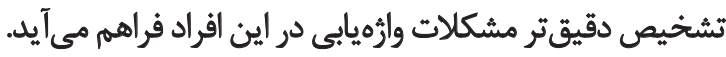

\section{بيشنهادها}

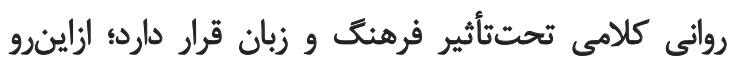

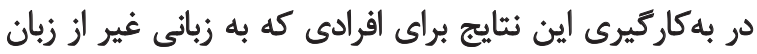

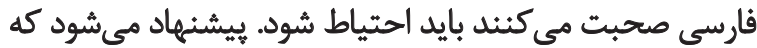

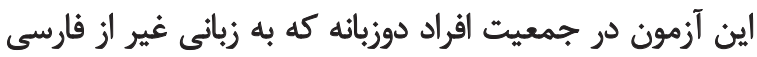

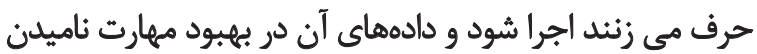
جمعيث مذكور مورداستفاده قرار تيرد.

$$
\text { تشكو و قدردانى }
$$

اين مقاله بركرفته از إياينامه كارشناسى ارشد در رشته

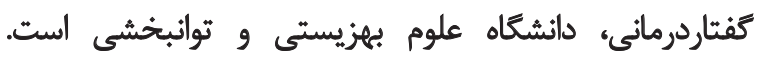

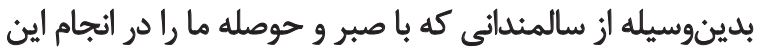

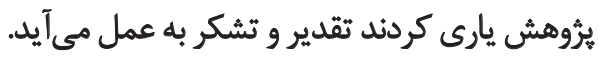

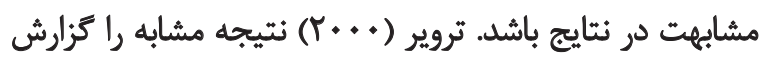

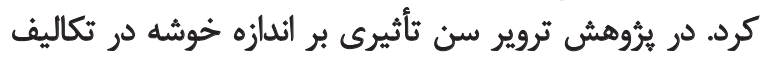
روانى واجى ندارد [هـ].

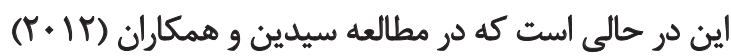

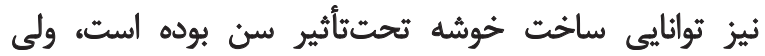

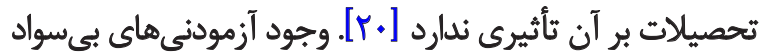

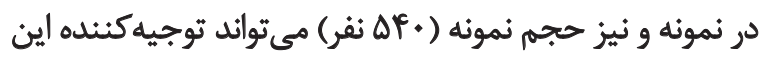

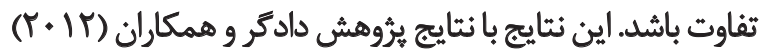

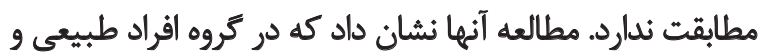

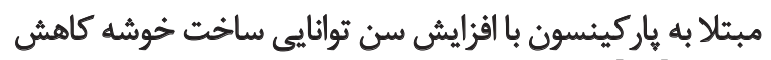
مي مينابد [rr]

نتايج ثروهش حاضر نشان داد توانايى انثقال و ساخت خوشئ

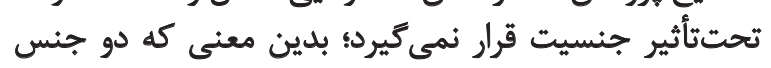

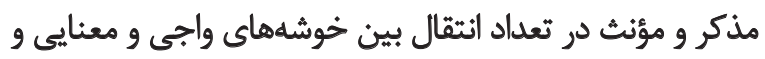

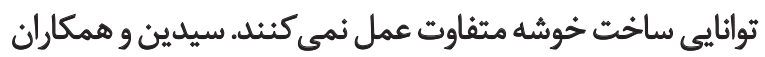

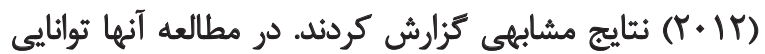

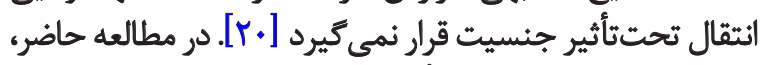

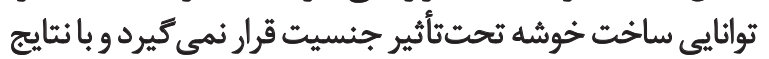

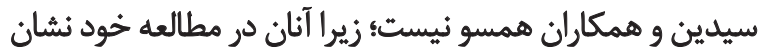

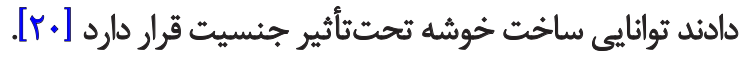

\section{تتيجهَيرى نهايى}

نتايج نشان داد در سالمندان عملكرد روانى واجى، روائى معناييى

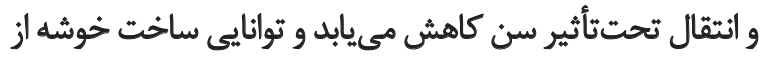

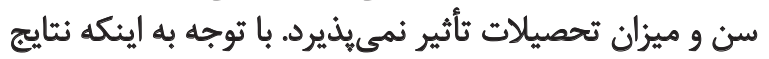

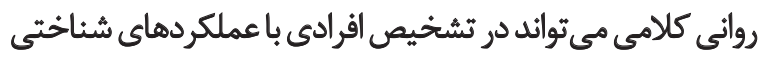

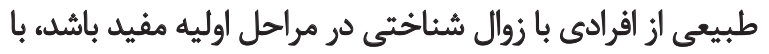

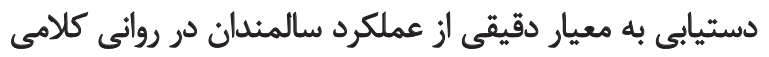

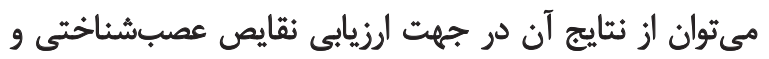

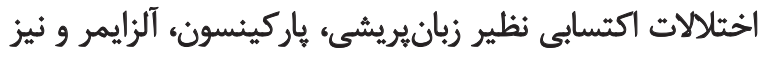

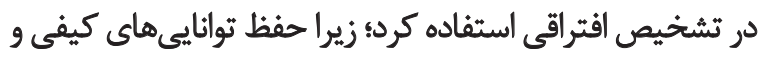

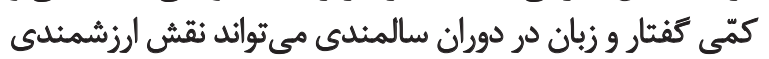

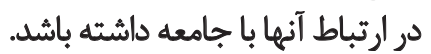

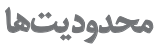

از جمله محدوديتهايي كه در اين برؤهش وجود برد داشت

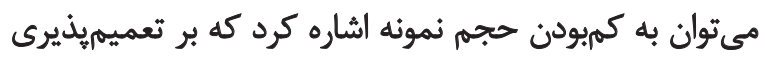

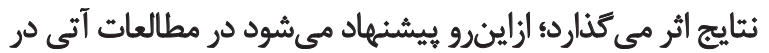

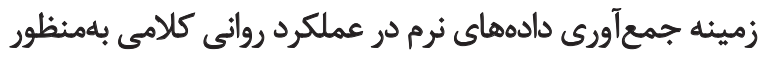

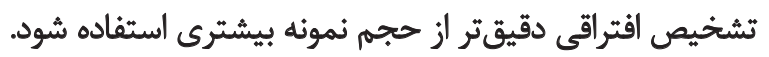

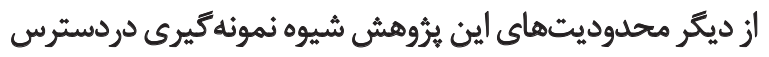

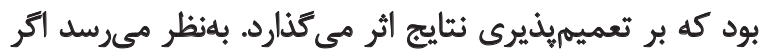

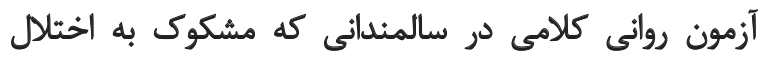




\section{References}

[1] Chapey R. Language intervention strategies in aphasia and related neurogenic communication disorders. New York: Williams \& Wilkins; 2008

[2] Snyder LS, Godley D. Assessment of word-finding disorders in children and adolescents. Topics in Language Disorders. 1992; 13(1):15-32.

[3] Kosmidis MH, Bozikas VP, Vlahou CH, Kiosseoglou G, Giaglis G, Karavatos A. Verbal fluency in institutionalized patients with schizophrenia: age-related performance decline. Psychiatry Research. 2005; 134(3):233-40

[4] Ebrahimipour M. [Verbal fluency test (Persian)]. Tehran: Paygahe Farhang; 2013.

[5] Troyer AK. Normative data for clustering and switching on verbal fluency tasks. Journal of Clinical and Experimental Neuropsychology. 2000; 22(3):370-78 .

[6] Jordan LM. Verbal fluency: norms for the Lakota population in semantic and phonemic fluency tasks [MSc. thesis]. North Dakota: University of North Dakota; 2014

[7] Kempler D, Teng EL, Dick M, Taussig I, Davis DS. The effects of age, education, and ethnicity on verbal fluency. Journal of the International Neuropsychological Society. 1998; 4(6):531-38.

[8] Van Der Elst W, Van Boxtel MP, Van Breukelen GJ, Jolles J. Normative data for the Animal, Profession and Letter M Naming verbal fluency tests for Dutch speaking participants and the effects of age, education, and sex. Journal of the International Neuropsychological Society. 2006; 12(1):80-89.

[9] O'Sullivan M, Jones D, Summers P, Morris R, Williams S, Markus H. Evidence for cortical "disconnection" as a mechanism of age-related cognitive decline. Neurology. 2001; 57(4):632-38.

[10] Kensinger EA, Corkin S. The neuroscience of aging. Boston: Boston College Publication; 2009.

[11] Bolla KI, Lindgren KN, Bonaccorsy C, Bleecker ML. Predictors of verbal fluency (FAS) in the healthy elderly. Journal of Clinical Psychology. 1990; 46(5):623-28.

[12] Hekmatpou D, Shamsi M, Zamani M. The effect of healthy lifestyle educational programs on the quality of life of the elderly in Arak. Indian Journal of Medical Sciences. 2013; 67(3-4):70-77.

[13] Maghsudnia Sh. [Primary health care for old adults in L.R.Iran (Persian)]. Tehran: University of Social Welfare and Rehabilitation Sciences Publication; 2005.

[14] Shemshadi H, Salehi A. [Speech and language disorder in aging (Persian)]. Iranian Journal of Ageing. 2006; 1(1):46-50.

[15] Brickman AM, Paul RH, Cohen RA, Williams LM, MacGregor $\mathrm{KL}$, Jefferson AL, et al. Category and letter verbal fluency across the adult lifespan: relationship to EEG theta power. Archives of Clinical Neuropsychology. 2005; 20(5):561-73.

[16] Tombaugh TN, Kozak J, Rees L. Normative data stratified by age and education for two measures of verbal fluency: FAS and animal naming. Archives of Clinical Neuropsychology. 1999; 14(2):167-77.

[17] Nejati V. [Correlation between working memory and verbal fluency among the elderly (Persian)]. Iranian Journal of Ageing. 2011; 8(3):412-18
[18] Machado TH, Frichman HC, Santos EL, Carvalho VA, Fialhi PP, Koenig AM, et al. Normative data for healthy elderly on phonemic verbal fluency task-FAS. Dementia \& Neuropsychology. 2009; 3(1):55-90

[19] Gladsjo JA, Schuman CC, Evans JD, Peavy GM, Miller SW Heaton RK. Norms for letter and category fluency: demographic corrections for age, education, and ethnicity. Psychological Assessment. 1999; 6(2):147-78.

[20] Seyedin S, Mardani N, Ebrahimipour M, Namdar M, MehriJalaei Sh. [Normative data of semantic fluency in adult Persian speakers (Persian)]. Journal of Modern Rehabilitation. 2012; 7(2):14-21.

[21] Ghoreishi ZS, Azimian M, Khorrami A, Rafiee SM, Alaghband J, Salavati M, et al. Lexical access in Persian normal speakers: picture naming, verbal fluency and spantaneous speech. Iranian Rehabilitation Journal. 2014; 12(20):16-20.

[22] Haugrud N. Describing cognitive change in normal aging and early-stage dementia using measures of verbal fluency [PhD thesis]. Saskatoon: University of Saskatchewan; 2012.

[23] Dadgar H, Shahbeigi S, Nikbakht D, Malmir F, Khodakarami Z. [Comparison of semantic and phonemic Clustering and switching in Parkinson`s disease and normal subjects (Persian)]. Audiology. 2012; 23(2):42-48.

[24] Brucki SM, Rocha MS. Category fluency test: effects of age, gender and education on total scores, clustering and switching in Brazilian Portuguese-speaking subjects. Brazilian Journal of Medical and Biological Research. 2004; 37(12):1771-777.

[25] Lanting S, Haugrud N, Crossley M. The effect of age and sex on clustering and switching during speeded verbal fluency tasks. Journal of the International Neuropsychological Society. 2009; 15(2):196-204

[26] Lotfi G. [Impairment screening test the validity and reliability of Persian Hamadan mini cog in the elderly, 2013 (Persian)]. [MSc thesis] Tehran: University Social Welfare and Rehabilitation Sciences; 2014 
